\title{
Vivir sin fundar. Política y psicoanálisis, una vez más
}

\author{
Nosotros | Tristan García | Editorial original: Grasset \\ Daniel Liotta* \\ Profesor de filosofía en clases preparatorias literarias
}

Recepción: 15 de diciembre de 2019; aceptación: 2 de febrero de 2020

\begin{abstract}
Resumen
Aquí estamos tratando de esbozar los principios de un vínculo político liberado de las presuposiciones imaginarias y simbólicas que definirían la naturaleza de los sujetos políticos. En otras palabras: de un vínculo político que no estaría determinado por la "sociedad" y las identificaciones imaginarias y simbólicas que impone al vínculo político. Tal política, que describimos como minimalista, debe ser indiferente a todas las consignas sociales: debe negarse a basarse en ellas. Decidir pensar en política de esta manera es sacar las consecuencias de una lección de la historia: basar el vínculo político en otro (Dios, raza, sexo, dinero, etc.) siempre determina justificar desigualdades, exclusiones, incluso asesinatos en nombre de este Otro y sus imperativos. Si rechazamos así cualquier fundamento político, ¿qué queda? Por un lado, el ejercicio de la igualdad y la universalidad de los derechos de los sujetos despojados de toda identificación social: deben llamarse "ciudadanos"; Por otro lado, el coraje de asumir un vínculo político sin la garantía de otro que encontraría este vínculo. Así, el minimalismo jurídico-político afirma que la conexión política de los ciudadanos tiene lugar en una no relación social: el principio de la conexión política es necesariamente la no conexión social. Sin embargo, concebir un enlace no subordinado a un significante maestro, tratar de "descomponer" el Otro y pensar en la relación en forma de no relación, es aprender de Lacan. Por lo tanto, es nuevamente confrontar la cuestión, tan a menudo estudiada, del vínculo entre política y psicoanálisis.
\end{abstract}

Palabras clave: Política | Correcto | Psicoanálisis | no relación

Live without founding. Politics and psychoanalysis, again

\section{Abstract}

My purpose here will be to try and outline the principle upon which a political bond, free from the imaginary and symbolical preconceptions which allegedly define the nature of political subjects can be founded. In other words, a political bond which would not be determined by 'society', and the imaginary and symbolic identifications it forces upon it. Such politics - that I define as minimal - ought to be impervious to the currently prevailing social discourses. It cannot possibly rely on upon them. Devising politics in such a way boils down to drawing the lessons from history : basing the political bond upon any Other (be it God, race, sex, money etc.) always ends up justifying inequalities, exclusions, even executions, in the name of that Other and its imperatives. Should one refuse to conceive of politics in such a way, what happens? On the one hand, the subjects - whom we now should call citizens -, thus freed of any social identification, will enjoy equality and universal rights ; on the other hand, one must have the courage to accept a political bond whose legitimacy does not stem from that Other. Thus judicial and political minimalism enables citizens to form political bonds independently of social relationships : political bonding necessarily entails a rejection of social bonding. To conceive of a bond which will not be subservient to a master signifier, to attempt to 'decomplete' the Other and to conceive of the relationship as a non-relationship cannot be done without the contribution of Lacan's works. Once again, it leads us to tackle the oft-discussed question of the connection between politics and psychoanalysis.

Keywords: politics | law | psychoanalysis | non-relationship

\section{A Jean-Louis Mattei}

"Un solo debate, siempre el mismo, el que se conoce desde que se tiene memoria, como el debate de la Ilustración”, Lacan, contratapa de los Escritos.

Adentrémonos en la interesante descripción social y política que propone Tristán García (2018) en Nous [No- sotros]. Propone distinguir las diferentes categorías (el "nosotros") que pretenden identificarnos: "hombres", "mujeres", "blancos”, “negros”, “árabes”, “judíos”, "migrantes", "franceses", "ricos", "pobres", "homosexuales", "heterosexuales". Podríamos por supuesto añadir "transgénero", “intersexuales", etc. Se observan relaciones de yuxtaposición, superposición, inclusión, 
pero también de rivalidad, exclusión, dominación, jerarquización, enfrentamientos y ocultamientos entre estas comunidades.

Podemos diferenciar con bastante claridad las clases imaginarias (las que representarían la realidad a través de representaciones) y que disponen para ello de propiedades distintivas internas: definen sus objetos a través de sus semejanzas y diferencias. Pensamos de inmediato en la identificación, o incluso la jerarquización, entre "hombres" y "mujeres", "negros" y "blancos". Distinguimos también las clases simbólicas, producto de simples distinciones de significantes a partir de las "variantes diferenciales" que produce el lenguaje: nos remitimos entonces a los "franceses" y "alemanes", a los "cristianos" y "judíos". En realidad, lo imaginario y lo simbólico se articulan: las clases simbólicas están cargadas de consistencia imaginaria y las representaciones se enfrentan a distinciones simbólicas; la diferencia imaginaria entre "hombres" y "mujeres", entre "blancos" y "negros" (identificados por sus propiedades inmanentes) está ligada a la lógica significante en virtud de la cual los significantes "hombre" y "mujer", "blanco" y "negro" solo tienen valor a partir de su diferencia. Las representaciones y diferencias significantes están constantemente entrelazadas.

\section{El minimalismo legal: encontrarse sin parecerse}

Ensayemos ahora un razonamiento. Apliquemos primero la hipótesis de la reducción. No eliminemos sin sentido las relaciones entre lo imaginario y lo simbólico sino que pongámoslas entre paréntesis y destaquemos una sola relación: la de seres humanos en tanto animales hablantes y los átomos legales definidos por derechos y deberes. Para representar la articulación de lo imaginario y lo simbólico, planteamos entonces animales hablantes (representados e identificados por propiedades que los homogeneizan y al mismo tiempo los distinguen entre sí) y los átomos definidos por un conjunto de derechos y deberes legales, partículas cuya existencia nace de su diferencia con las demás, ya que los derechos de cada una tiene sentido y existencia legal efectiva sólo en relación con los deberes de las demás. ${ }^{1}$ Más exactamente, cada ser humano (cada animal hablante) debe poder superponerse a un átomo legal. ${ }^{2} \mathrm{Al}$ analizarlos con este nivel de abstracción, estos sujetos se vacían de particularismos imaginarios y simbólicos, y sólo se identifican por sus derechos y deberes legales. Supongamos entonces que estos sujetos están vinculados de tal manera que instituyen las leyes que rigen sus relaciones. ¿Qué se puede deducir de esto?

Podemos plantear una primera propuesta: no es posible implementar el privilegio legal. En efecto, todos los privilegios legales deben ser eliminados, prosiguiendo con la hipótesis de reducción, ya que se basan en reivindicaciones particulares, históricas y culturales, es decir, en identificaciones imaginarias y en diferencias simbólicas (la raza superior, el amor y el culto al Dios verdadero, los poderes de la sangre y el censo, los derechos de los machos o de los blancos, etc.). ¿Qué queda entonces luego de esta reducción? Los derechos y deberes universales, es decir, derechos y deberes que deben ser regulados por un minimalismo jurídico-político cuyo principio es el universal: que los derechos de cada uno sean los de todos, y que los derechos de cada uno estén limitados por la posibilidad de que todos puedan ejercer esos mismos derechos. Hablamos de minimalismo por dos razones que están relacionadas: por un lado, se elimina la compleja interacción de privilegios y desigualdades en favor de la simplicidad de los derechos universales (simplicidad que no significa una ausencia de problemas sino, por el contrario, la reiteración, ante cualquier dificultad política, de la cuestión de la igualdad jurídica); por otro lado, el sistema jurídico-político, regulado por esta simplicidad, impone lo universal pero no determina la naturaleza de todos los derechos que deben ser universalizados; lo que significa, insistamos en esto, que no determina los sistemas jurídicos que estructuran las actividades económicas. Es necesario, sin embargo, que entre todos los derechos esté el de participar en la institución de las leyes. De hecho, si ese derecho se reserva solo para unos pocos, estaríamos volviendo al complejo sistema de privilegios. Es por eso que todos los sujetos tienen la posibilidad de declarar sus derechos y deberes. El derecho representa entonces otra cosa que la distribución del goce, según la formulación de Lacan: también puede ser el ejercicio asumido del deseo.

Los derechos de cada sujeto están por lo tanto limitados por los derechos idénticos de los demás. En este caso, "cada" se refiere a cada uno y a todos, aunque referirse a "cada uno" no sea políticamente sencillo: representa la alianza de lo universal y lo singular, y la posibilidad de desplegar lo singular dentro de los límites del respeto a lo universal. Si llamamos a estos derechos "libertades", se exige entonces una igualdad de libertades que reconozca la legitimidad de lo singular y lo universal.

Pretender igualdad y libertades es algo obvio. ¿Pero qué implica esta obviedad? El minimalismo legal se apli- 
ca a sujetos vaciados [évidés]: reconoce la existencia de ellos y los nombra para poder individualizarlos. Pero no dice nada, por un lado, sobre el ejercicio singular de sus derechos y por otro, sobre sus particularismos, ya que éstos, como dijimos, se pusieron entre paréntesis. El minimalismo legal considera así a los sujetos presentes como átomos legales propietarios de sus cuerpos, $\mathrm{y}$ los considera ausentes en tanto que permanece sordo al ejercicio de esa propiedad y anula sus identificaciones y diferenciaciones.

Esto supone una diferenciación de lo jurídico-político, en donde se ubica el minimalismo legal, y la "sociedad", el lugar de estas identificaciones y diferencias. Gracias al juego de la presencia/ausencia, lo mínimo se limita a hacer composibles las libertades de los sujetos. Mantiene fuera de su discurso sus formas de deseo y de goce, es decir, las maneras de ejercer sus libertades. Esto no significa de ninguna manera que se prohíban los conjuntos constituidos por vínculos imaginarios y simbólicos. Llamemos "grupos" o "comunidades" a esos vínculos y llamemos "principios rectores" a las justificaciones de esos vínculos. Se pondrán entre paréntesis en la medida en que no constituyen la base del vínculo político y jurídico. Respecto a ese vínculo, no son ni fundamentales ni prohibidos; son por lo tanto indiferentes. Por eso se permiten, siempre y cuando no transgredan los principios de lo mínimo. Debemos por lo tanto rechazar las semejanzas imaginarias y las referencias simbólicas como principios políticos para que los sujetos puedan afirmar libremente su identidad o referenciación (nosotras mujeres, nosotros hombres, homo-, o hetero- o transexuales, nosotros corsos, nosotros chalecos amarillos ${ }^{3}$ ) o que también tengan la posibilidad de rechazar que se resuelva su existencia a través de ellos. Ya sea en manifestaciones o en enfrentamientos, ya sea que legitimen ciertas referencias o que las rechacen, los sujetos están unidos político-jurídicamente cuando se los deslinda de cualquier obligación (solo el minimalismo legal hace posible que se despliegue lo singular respetando lo universal). Por lo tanto, se vinculan cuando se los desvincula. Ningún parecido, ningún punto de referencia, excepto el minimalismo legal, los une políticamente. Lo que une a los sujetos es entonces lo que los aleja y lo que los singulariza: el ejercicio de sus libertades.

La articulación de lo singular con lo universal nos obliga de esta manera a pensar en lo universal no como forma homogénea, es decir, segregada, ya que el mismo/ los mismos derechos se cumplen en la diferencia/en el ejercicio de los derechos. Los sujetos constituyen así una clase que se afirma de manera paradójica, una clase que podríamos nombrar, gracias a Lacan (2001), si sacamos la fórmula de su contexto, como conjunto de "desordenados dispersos” (p. 573), un conjunto que une a los sujetos por el único vínculo del ejercicio singular de sus derechos idénticos. Jean-Claude Milner (1983), siguiendo a Lacan, ya había propuesto ese principio: "la misma instancia que los hace parecerse y acoplarse es la que los separa; lo que los separa es lo que hace que se relacionen entre sí, sin por eso parecerse ni vincularse” (p. 118). Catherine Kintzler (2007) enuncia de manera brillante esta paradoja de la vinculación: "el principio de suspensión del vínculo social aparece como constitutivo del vínculo político" (p. 32). ${ }^{4}$

Puede decirse que los sujetos políticos producidos por este vínculo son "ciudadanos", pero siempre y cuando esta definición también contenga su acepción extraña y preocupante: designar una singularidad político-jurídica definida por derechos universales que contribuye en producir, apartada de las diferencias imaginarias y distinciones simbólicas, sin identificaciones sociales ni puntos de referencia, es decir, fuera de la comunidad, pero manteniendo su facultad de actuar dentro de los límites de lo universal. No se trata de un sujeto que experimenta un aislamiento, que solo reacciona cuando escasean los encuentros queridos, sino que es una soledad en lo universal - ya que los derechos y deberes legales de cada persona son los de todos, y no todos pueden controlar el uso que cada persona hace de sus libertades. Es una soledad que confronta a cada ciudadano con alteridades siempre pluralizadas, ya que cada persona puede hacer un uso singular de su cuerpo y su palabra. ${ }^{5}$

\section{El grupo y el desafío político}

Pero no hay nada adquirido. Sería de extrañar que todos los sujetos consientan libertades sin propiedades previas garantizadas, que al mismo tiempo fundarían esas libertades, vínculos que se hacen carne en la disyunción, encuentros sin semejanzas y como decíamos, identidades sin identificación. En resumen, es dudoso que todos los sujetos consientan sin resistencia y sin dolor en convertirse políticamente en "ciudadanos".

De ahí surge sin duda el desarrollo de "grupos" y "comunidades" y la necesidad de unirse en la creencia de la semejanza y en la identificación con algún "principio rector”. Es probablemente lo que determinaba Lacan (1974- 
1975) al afirmar: "no hay duda de que los seres humanos se identifican con un grupo. Cuando no se identifican con un grupo, están jodidos, están condenados al encierro" (p. 166). Pero meditemos en la fórmula "mido el efecto de grupo en cuanto a lo que agrega de obscenidad imaginaria al efecto de discurso" (p. 474). Lo interpretamos de la siguiente manera: el efecto de discurso es necesariamente un efecto de goce, lo simbólico está necesariamente cargado, impreso e infiltrado de goce. El cuerpo, el cuerpo hablante vivo, está sujeto al goce. No es captado sólo por lo imaginario, es decir, sometido a semejanzas especulativas; no se refiere y se somete sólo al poder simbólico. Por esta sumisión, se constituye como cuerpo de goce; goza de él mismo, en su singularidad se podría decir. Ahora, a este efecto inevitable del discurso, el "grupo" añade la exhibición del goce de parecerse. La obscenidad imaginaria condena así al grupo a representar y cultivar tal goce.

Los psicoanalistas constituyen por el contrario "desordenados dispersos”. En efecto, Lacan (1974-1975) había especificado que "es imposible que los psicoanalistas formen un grupo" (p. 475), añadiendo: "La observación presente de la imposibilidad del grupo analítico es también lo que funda, como siempre, lo real. Lo real es esa misma obscenidad: así también "vive" (entre comillas) como grupo" (p.475). Los cuerpos hablantes que componen el grupo analítico están así animados por un "real" que debemos entender en este caso a partir de sucesos de goce: de parecerse al reunirse. Pero los psicólogos justamente deben enfrentarse a ese imposible (el de deshacerse del "grupo" y escapar de su obscenidad) y si logran llegar a esa altura, es posible proponer una lección política. Cuando no están a la altura, lo que se logra a veces con la experiencia, ¿renuncian en ese caso a su supuesto deseo analítico? Al no ser analista, no sabría responder. Retengamos lo que nos parece esencial: "el discurso analítico (es mi camino) es precisamente el que puede fundar un vínculo social depurado de cualquier necesidad grupal" (Lacan, 1974-1975, p. 474). Para establecer ese vínculo, los analistas encuentran en su discurso, el del análisis, una "muralla" contra la obscenidad. En efecto, el deseo del analista es ocupar el lugar, necesariamente vacío, del objeto singular del goce; en el análisis debe entonces permitir que se escuche la verdad de los seres hablantes, llamada "castración", según la cual el sujeto y el goce se disocian. Es decir, la ley por la cual los seres hablantes, en tanto seres hablantes, se reúnen en la no relación, disociándose de sí mismos y de los demás. Y de esta manera, ¿no es la "posición del analista" una "muralla contra el grupo”? ¿No obstaculiza por lo tanto el obsceno engaño que hace que el goce vital del grupo persevere y brille? ${ }^{6}$

El origen de este engaño reside entonces en el horror de lo "real", que podríamos caracterizar en este caso como el horror de la castración, el horror de la relación con uno mismo y con el otro en la no relación, y por lo tanto el horror de la división subjetiva que es la no relación con uno mismo y con el otro. Se entiende: no el horror de la diferencia que altera al enamorado del grupo, un horror banal que se relaciona de forma imaginaria con las delicias de asemejarse, sino el horror de lo real, el horror velado que provoca y sostiene el horror de lo disímil. El grupo es así una protección contra lo real. La lección del psicoanálisis es clara. No es que la ciudadanía y el pensamiento de la ciudadanía, tal como lo entendemos, eran inexistentes antes del psicoanálisis; pero ahora, gracias al psicoanalista, podemos arrojar cierta claridad sobre la necesidad y la dificultad de lo mínimo. Precisemos esta enseñanza.

\section{No tapar el agujero en la política}

El discurso psicoanalítico, tal como lo pretendía Lacan (1974-1975) "puede fundar un vínculo social depurado de cualquier necesidad grupal” (p. 462). De esta manera, arroja luz sobre la decisión de no "fundar" el vínculo político y transformarlo en un "grupo", con la condición de que el término "fundado" signifique en este caso reunirse alegando semejanza; de esa manera, en "un intento grotesco", se pensó en "fundar" por medio de la raza "un Reich denominado Tercero". Por lo demás, el discurso analítico arroja luz sobre la decisión de vaciar a los sujetos políticos de las determinaciones imaginarias y simbólicas que fundan los parecidos y las jerarquías en el grupo.

Justamente, fundar es inventar un "principio rector" [maître-mot] que justifique el vínculo, dando así la ilusión de que se puede eliminar la incompletud de lo simbólico y representar y dominar lo real de la no relación. Esta incompletud significa no sólo que no puede haber una garantía última de la verdad del discurso, ya que cualquier garantía está condicionada por el ejercicio del discurso, sino también que la verdad de la castración no se puede controlar. Pretender anular esta incompletud significa concederle cierto estatus al Otro, lugar de la palabra y de las reglas que estructuran las relaciones entre los sujetos. Así surge el discurso político del principio rector: 
- que pretende desenvolverse en nombre de un Otro - Dios, Raza, Sexo o Sangre - a quien otorga plenitud, es decir, lo dota de una verdad absoluta, colocándose así en la posición de amo (Nietzsche diría "ídolo");

- pretende conocer a ese Otro, conocerlo sin carencias, en su integridad;

- y en su nombre, funda las semejanzas y diferencias en la verdad, los privilegios y las subordinaciones que estructuran el grupo ( $\mathrm{y}$ vuelven entonces aguantables a través de lo disímil, en todos los sentidos de la palabra, el horror de la no relación).

Así trabajan en el campo político los discursos del Otro y así se fundan los "valores" políticos de homogeneidad moral, social o religiosa: poniendo las bocas de sombra en movimiento, escuchándolas, recogiendo los principios que esbozan las condiciones de poder, las desigualdades y las diferencias. Se suele escuchar que la historia nada enseña, o que la única lección de la historia es no ofrecer ninguna lección. Sin embargo, acá sí se impone una lección. Encontrarse en una supuesta semejanza equivale a ponerse en posición de hacer gozar a ese Otro obsceno y cruel que exige la reducción o incluso el sacrificio de los diferentes, a menudo a costa de la muerte (martirio o reclutamiento) de los semejantes. Se pretende también hacer gozar a su(s) representante(s): hacer gozar a Dios y a sus fieles más devotos, o a la Raza y a Hitler. Tal es el efecto cuando se reprime el real político de la "no relación" y cuando el grupo hace soportar el horror de la no relación a lo diferente. Y hay por supuesto diferencias de grado, que son muy importantes. Sabemos lo que nos depara el destino banal: la desigualdad, para imponer el lugar que les corresponde a los que el Otro considera inferiores, a los que no pueden pagar el censo, a los que no son del sexo legítimo, o que no son de la buena sangre o de la buena tierra, a los que no honran al Dios que les conviene o protestan contra el culto que se le rinde. $\mathrm{O}$ peor, tal vez: aquellos que no honran a ningún Dios o que niegan su fe. Sabemos que hay medidas más pesadas: el confinamiento o la exclusión. Y sabemos finalmente lo que le sucede a los cuerpos hablantes en el punto más extremo de degradación: el exterminio.

Por el contrario, no aceptar los principios rectores representa rechazar la pretensión de eliminar la incompletud del Otro. Es negarse a "ocuparse a tapar el agujero en la política” (Lacan, 1974-19755, p. 555), un trabajo que Lacan atribuye a Heidegger. Por eso dijimos al principio de nuestro estudio que decidimos reducir lo imaginario y lo simbólico de los animales hablantes y sus derechos: era para no obrar en "tapar el agujero en la política", o mejor dicho: obrar para no taparlo. Al goce de lo fundante, y por lo tanto de la semejanza, debemos responder con el deseo de libertad, inmune a los principios rectores. Uno puede ciertamente responder que lo mínimo constituye tal fundamento. El equívoco concepto de "fundamento" estará siempre en juego, pero no debe por eso impedirnos la distinción entre un discurso rector (que crea las semejanzas y diferencias) con el principio que disocia a los animales hablantes, uniéndolos. No distinguirlos es negarse a diferenciar entre la desigualdad e igualdad fundada por los grupos pero también la igualdad producida por el minimalismo legal. Significa abstenerse de diferenciar la uniformidad que los imperativos de semejanza hacen prevalecer en los grupos y la universalidad que permite singularizar a cada persona dentro de los límites de lo universal.

La primera propuesta (colocar como agentes políticos a los sujetos vaciados) puede rápidamente desarrollar más propuestas. Y en primera instancia, esta segunda propuesta: los sujetos políticos no tienen fundamento, pero tienen una verdad. O más bien, son poseídos por ella cuando se transgrede la igualdad de libertades y surge entonces la desigualdad, la exclusión o el exterminio. Esta verdad puede expresarse en el miedo, el terror o la lástima, en la experiencia de lo intolerable o en la sequía y frialdad de una crítica.

La verdad consiste en escuchar lo real de la no relación. La verdad siempre es aquello que fractura y rompe los supuestos saberes de semejanzas y diferencias. Requiere por lo tanto luchar, mientras sea materialmente posible, contra el goce político de un fundamento. De la misma manera que "ciudadano" puede ser apropiado para significar el sujeto políticamente vaciado, Res-publica no es necesariamente un significante inapropiado para manifestar esa exigencia, aunque sea repudiado y deba refugiarse en las alcantarillas. Con una condición, sin embargo: hacer resonar el vacío de esa Cosa - res -, sin querer apaciguarla, sin querer reducirla por su articulación con lo imaginario y lo simbólico; en definitiva, preservar su condición de vacío que los ciudadanos deben emplearse en no tapar. Nos encontramos una vez más con los matices de la homonimia, cuando un partido político de derecha (pero la izquierda tampoco se queda atrás) utiliza precisamente la palabra para llenar el hueco: esa es la única intención cuando se refieren a los "valores de la República”, a la "reunión”, al "buen francés" en 
contraposición a todos los "peligrosos". Solo recordemos que en el siglo XIX pero también en el siglo XX, uno podía morir por mencionar una palabra, en Francia y en otros lugares. La verdad incluye así un imperativo: no basarse en ningún fundamento y descartar cualquier discurso que pretenda reducir el vacío de la Cosa.

Por eso - tercera proposición - los principios rectores deben ciertamente someterse a la crítica, pero, cuarta proposición, resistir a los principios rectores tiene más sentido que obrar en destruirlos. Supone que los críticos produzcan conocimientos (del fundamento y la semejanza política) que exijan la verdad y puedan articularse con ella y no se le opongan, es decir, conocimientos a través de los cuales la universalidad se ejerce y problematiza y se hace visible el engaño del fundamento político, así como también aquellos conocimientos en los cuales se puede dominar intelectualmente los particularismos simbólicos e imaginarios. El minimalismo legal debe ofrecer, gracias a su instrucción, la posibilidad de ejercer hábilmente sus propios derechos y orientarse intelectualmente en el seno de los principios rectores. La instrucción debe permitir que los sujetos se pongan a la altura de las razones que prohíben que se hable de la diferencia sexual, la herencia y las desigualdades económicas para instituir un vínculo político. Limitar los prestigios del imaginario sexual, hereditario o económico, restringiendo sus poderes simbólicos, es una manera de obrar para descompletar al Otro (del Sexo, Raza o Riqueza), es decir, para vaciarlo de toda sustancia unificadora.

Pero para que esta exigencia se vuelva un principio, es necesario institucionalizar la producción y la transmisión de esos conocimientos. En efecto, según el minimalismo legal y su principio de universalidad, nadie tiene más derecho que otro en meditar, producir y aplicar derechos y deberes, y todos deben aprender a ejercerlos. Todos los sujetos políticos deberían por lo tanto estar en condiciones de apropiarse de los conocimientos de los ciudadanos. En este sentido, valoramos la función de la escuela. Debe entonces imponerse en un solo movimiento como límite de la sociedad - ya que los grupos y sus semejanzas no deben reinar en ella - y como un instrumento de crítica de los principios rectores de la política. No digamos que la escuela funda el vínculo político, lo que implicaría que la producción de derechos se cancelaría en pos del dominio de los conocimientos. El conocimiento no se concibe como fundante, y la política republicana no es la ciudad platónica. La escuela permite arrojar luz sobre la producción y el ejercicio de las libertades; no las somete legalmente a su autoridad.

\section{Descompletar la política, descompletar al Otro}

Principios del minimalismo: colocar a los sujetos desligados de las garantías imaginarias y simbólicas en el lugar de agentes políticos; colocar el vaciamiento de la Cosa en el lugar de verdad; colocar los principios rectores en el lugar de lo que debe trabajarse y los conocimientos racionales en el lugar de la producción. Consideramos que tanto el esclarecimiento del psicoanálisis como la referencia a la filosofía política de Catherine Kintzler permiten determinarlo. La filósofa trabaja el concepto de "laicidad", no sólo para explicitar un concepto político regional, sino también para definir con rigor el vínculo político legítimo. Y justamente, Kintzler se nutre no sólo de Condorcet, sino también de Lacan y Milner. Podemos llegar a decir que es lo mismo decir que una lectura de Lacan y Milner permite pensar en este vínculo y que este vínculo puede ser pensado gracias a un cierto "regreso a Condorcet". ${ }^{7}$

Somos muy conscientes de que la producción de leyes escapa con frecuencia a los ciudadanos. Sabemos también, gracias a los sociólogos e historiadores, que el ejercicio de las libertades, que separa y une a los sujetos, está socialmente condicionado por el estado de la moral y la "cultura". ¿Y qué sentido tienen estos derechos, si sabemos que su ejercicio nos condena a soportar los determinismos y "condicionamientos" sociales? El minimalismo jurídico-político no ignora en absoluto estas grandes dificultades, pero la política se dice de muchas maneras. Llamemos lo político a la existencia de relaciones de poder dentro de una cultura. Es muy digno e incluso esencial accionar sobre lo político, es decir, explorar y modificar las relaciones de poder, estudiar su historia, analizar su economía actual, explicitar los vínculos que tienen con los conocimientos y sacar a relucir las contingencias de los poderes en los lugares en que nos conformábamos con las ilusiones de la necesidad. Es esencial poner en evidencia la contingencia de los deseos, goces y formas culturales de hacer las cosas para poder modificar los modos políticos de la existencia. Y las reivindicaciones de las comunidades, cuando "problematizan" las leyes y la moral, pueden perfectamente instruir figuras erróneas de lo universal; la legítima lucha que se niega a restringir la universalidad del matrimonio al vínculo heterosexual constituye un auténtico ejemplo de esto. Las comunidades no reducen entonces sus demandas a su particularismo comunitario. Por eso una de las lecciones de Foucault (1994a/1994b) es más importante que otras: es sólo en un primer momento, cronológica y tácticamente, que los movimientos de "liberación" de la homosexualidad de- 
ben reivindicar una identidad homosexual y una semejanza entre homosexuales. Deben liberarse del principio rector "sexo" y trabajar, no para establecer su semejanza como un principio político, sino para inventar sus propias singularidades de placer y deseo.

El minimalismo, sin embargo, define un modo de lucha otro que la transformación de la política, aunque no se oponga a esta lucha. Se afirma como una política limitada ya que es una política del límite jurídico. No pretende imponer la justicia en los juegos indefinidos de los poderes y comunidades. Trabaja en limitar esos poderes de tal manera que no gobiernen las leyes y el pensamiento. Es necesario mencionar al respecto lo que Deleuze y Guattari (1991) afirmaban sobre los derechos humanos, a modo de fuerte reproche: "no dicen nada sobre los modos de existencia inmanentes del ser humano con derechos" (p. 103). El minimalismo jurídico-político tampoco dice nada sobre estos modos de existencia, pero se esfuerza por liberarlos de la dominación de los grupos; de este modo, se esfuerza por dar a todos la posibilidad jurídica e intelectual de inventar un futuro que no se reduzca a un futuro comunitario. Hace que tales "subjetivaciones" sean legalmente posibles. Al desplegar una política de singularidad subjetiva, prescribe las condiciones universales de respeto de esta singularidad y no la determina, lo que sería negarla. Lo mínimo, como dijimos al principio de nuestro trabajo, se opone a la complejidad de los privilegios y no determina la multiplicidad de derechos y deberes. Rechaza además el proyecto de una política total y no determina "modos de existencia" culturales. Reconoce así, en el campo de la política, la incompletud del Otro que reduce a su condición mínima y necesaria, regulando las relaciones jurídicas entre los ciudadanos. ${ }^{8}$

La experiencia histórica nos muestra que la religión afirma con frecuencia ocupar el lugar de principio rector, pero el vínculo de lo mínimo con la religión no se reduce a una secuencia histórica. Este vínculo constituye más bien la punta más afinada de lo mínimo y el cristal en el que manifiesta sus implicaciones más profundas. ¿Cuál es ese enlace? El minimalismo jurídico-político no se opone a la religión, sino al clericalismo, que erige a la religión como fundamento del vínculo político. Es cierto que el Otro divino no se afirma, pero tampoco se niega (el laicismo no es un ateísmo); se descompleta políticamente porque el minimalismo afirma esta exigencia: que el Otro deje de ser lo que los sujetos hacen hablar para garantizar que se asemejen cuando se unen políticamente. Es lo que aprendemos de la relación del minimalismo respecto con la religión: ¿por qué descompletar la política si no es para descompletar al Otro? Y - esta es también el eventual aprendizaje del psicoanálisis - ¿por qué descompletar el Otro, si no es para dar al sujeto la oportunidad de inventar una singularidad desglosando identificaciones y certezas simbólicas?

\section{Apólogo: ¿̨la ruina social del minimalismo jurídico- político?}

Nadie puede negar que el minimalismo jurídico-político se prohíba, se reprima o se destruya a partir de los procesos económicos, políticos o culturales. Conocemos las dificultades - quizás haya que hablar de imposibilidad - de que el minimalismo se inscriba en la historia; allí reinan los grupos y su goce complaciente. Tampoco podemos ignorar que el minimalismo sea actualmente víctima de ataques en Francia, donde se había instituido como principio, como claramente lo demuestra su historia.

Ya identificamos el reto político que suponía el enfrentamiento de los ciudadanos con el "hueco" político. Este primer desafío se desdobla en otro desafío más, que vincula la política con las dificultades cotidianas de cada uno. En efecto, el ciudadano puede hacer todo lo que no esté prohibido al respetar los derechos de todos. De esta manera, ejerce sus libertades. Pero cuando se encuentra con la libertad singular del otro, este ejercicio a menudo toma la forma del consentimiento. El consentimiento se enuncia y es performativo: expresarlo es constituirlo y "darlo". Sin embargo, la ley ignora la división subjetiva que experimenta lo performativo. Ser propietario de su cuerpo significa disponer de él; es usarlo y gozarlo, cargando por ejemplo un niño de otra persona o consintiendo en un determinado modo de relación sexual. Pero el goce es muy poco controlable, perturba, deshace la subjetividad y puede incluso destruirla. Ocasionalmente, la ley compensa el desconocimiento de la división subjetiva invocando, según el caso, la edad, la situación social o el estado psicológico del sujeto que consiente. Pretende de esta manera trabajar en la contención de las perturbaciones del goce. El hecho es que las libertades del ciudadano se enfrentan, por principio, a los deseos y placeres singulares con sus posibilidades jurídicas de cumplimiento, incluso cuando los goces destruyen. Al contrario probablemente de las "sociedades tradicionales", que las sometían a sus "fundamentos" y prohibiciones culturales. El legislador intenta ahora inventar nuevos principios rectores que deban respetar las libertades y que deban sin embargo incluir el goce cuando transgredan demasiado las normas sociales (como 
la "dignidad"). 9 Suspendidas entre estas dos exigencias, las libertades son por lo tanto frágiles, arriesgadas para el sujeto que las ejerce y sospechosas para los políticos que quieren evitar esos riesgos.

Nos referimos a las normas sociales. Se impuso efectivamente un principio rector que no dejó de crecer desde el siglo XIX, buen aliado del dinero, que acompañó en varios momentos políticas raciales y sexistas y ahora reina sola, en oposición a los principios rectores religiosos: la "sociedad", que reconoce con frecuencia el valor de la "dignidad" como un imperativo jurídico. El principio rector "sociedad" no se basa, como en los principios rectores anteriores, en la palabra de un Otro que debería justificar desde afuera el vínculo político, la Revelación o la Raza. Hoy en día, el pensamiento "liberal" abandona con frecuencia estas apariencias en favor de la forma del vínculo erigido en ideal (una forma que sirve a los intereses del capitalismo, como lo demuestran las investigaciones empíricas, dicho sea de paso). "Forma del vínculo" significa: se supone que el Otro funda el vínculo, debe garantizar la legitimidad de la unión y asegurar su homogeneidad, pero este Otro no es otra cosa que esa misma reunión en la inmanencia de su existencia y al servicio del capitalismo. A partir de ese momento, esa existencia y ese servicio se convierten en fines en sí mismos y el discurso del vínculo sólo se justifica por el vínculo de los discursos e intercambios capitalistas supuestamente incriticables (como la "comunicación" y sus almas gemelas, la "transparencia" y la "libre circulación de mercancías" que supuestamente respetan y protegen a la "sociedad"). ${ }^{10}$

De esta manera, la sociedad, el Narciso moderno, segrega sus normas reflexionando sobre sí misma y planteando el hecho de la socialidad mercantil como un deber. ${ }^{11}$. En nombre de su complejidad efectiva, reivindicaciones identitarias nacen y se desarrollan, las del "nosotros" que mencionamos al principio del trabajo, a menudo aparentemente opuestas a su poder. Sin embargo, en nombre de un imperativo de reflexión, las comunidades exigen que las representaciones electivas, las instituciones culturales, y especialmente los medios de comunicación, reflejen el fulgor social y se vuelvan "sensibles a la diversidad”. El comunitarismo, que a veces toma la apariencia de una lucha antisocial, es inseparable de un amor a la sociedad. Se origina en ella y pretende dominarla. Sin embargo, como sostiene García (2018), las geografías sociales del "nosotros" están destinadas a metamorfosearse, a superponerse sin cesar y a entrar en relaciones de rivalidad y prioridad siempre renovadas, de tal manera que ningún principio inmanente puede preservar un "nosotros" determinado y comprometerlo a respetar a otros "nosotros". ${ }^{12}$ Y agregaremos: instituir sus poderes como principio político significa entregarse a un frenesí y una dispersión imaginarias y simbólicas que arruinan lo singular y lo universal.

Criticar a la "sociedad", negarse a que pretenda ser ilimitada, equivale a enseñarle que sus vínculos no deben establecer la justicia, y es asentar el principio de que solo se debe exigir legalmente al sujeto para el respeto de sus deberes como ciudadano. En términos más generales, luchar a favor del minimalismo es asegurar que nuestro presente no se reduzca a una elección entre la trascendencia religiosa y la inmanencia de las relaciones sociales. De esta manera, el imperativo nos parece siempre el mismo, a favor de una política de singularidad subjetiva: preservar el hueco de la política contra los discursos y prácticas que pretenden - juguemos con lo equívoco -cegarla.

\section{Referencias}

Deleuze, G. y Guattari, F. (1991). Qu’est-ce que la philosophie? [¿Qué es la filosofía?]. París: Les éditions de Minuit.

Fabre-Magnan, M. (2018). L'institution de la liberté [La institución de la libertad], París: PUF.

Foucault, M. (1975). Vigilar y castigar. Nacimiento de la prisión. París: Editions Gallimard.

Foucault, M. (1994a). La volonté de savoir [La voluntad de saber], "Non au sexe roi” ["No al sexo rey”], No 200, Dits et écrits, vol. III, París: Gallimard.

Foucault, M. (1994b). “Le triomphe social du plaisir sexuel : une conversation avec Michel Foucault”, ["El triunfo social del placer sexual: una conversación con Michel Foucault], vol. IV.

García, T. (2018). Nous. París: Le livre de poche.

Kintzler, C. (1984). Condorcet, l'instruction publique et la naissance du citoyen [Condorcet, la instrucción pública y el nacimiento del ciudadano]. París: Gallimard.

Kintzler, C. (2007). Qu'est-ce que la laïcité ? [¿Qué es la laicidad?]. París: Vrin.

Milner, J.C. (1983). Les noms indistincts [Los nombres indistintos]. París: Seuil. 
Milner, J. C. (2003) Las inclinaciones criminales de la Europa democrática. París: Verdier.

Milner, J.C. (2017). Consideraciones sobre Francia, Conversación con Philippe Petit (París: Les éditions du Cerf.

Lacan, J. (1974-1975). RSI, Séminaire 1974-1975. París: Editions de l’Association Freudienne Internationale.

Lacan, J. (2001). "Préface à l'édition anglaise du Séminaire XI" ["Prólogo a la edición inglesa del Seminario XI". En Autres écrits [Otros escritos]. París: Seuil.

1 Decimos: de existencia y sentido legal. Puedo entender el sentido de un derecho sin entender el sentido de un deber, o escuchar un deber que contradice el derecho; pero no puedo dar un sentido legal a un derecho sin plantear la variante diferencial con un deber que constituye su inversión. Algunos ejemplos sencillos: el ejercicio por todos del derecho de propiedad presupone que los demás respeten la prohibición de infringir la propiedad ajena; el ejercicio del derecho de réplica por una persona "designada o nombrada" en un órgano de prensa presupone que el director de ese órgano respete su deber de entregar la respuesta; el ejercicio por los empleados de sus derechos presupone que los empleadores respeten sus propias obligaciones, etc. Estas relaciones son recíprocas.

2 Y no al revés, ya que hay personas jurídicas “morales” más que "naturales”.

3 Movimiento social de protesta nacido en Francia en octubre de 2018 como respuesta al alza de los combustibles. [Nota del traductor].

4 Nuestro artículo no podría haber sido escrito sin este estudio y sin Les noms indistincts de Jean-Claude Milner a los que se refiere la nota anterior.

5 Con este nivel de generalidad, de nada sirve cuestionar la escala jurídico-política. Recordemos que no sólo existe una ciudadanía-nacionalidad sino también una ciudadanía internacional, como la ciudadanía europea. Recordemos también que existe un derecho internacional. El desafío es que en cada escala se afirme el principio del sujeto vaciado. p. 474)

Es decir, "llama a este baluarte contra el grupo, la posición del analista como se define en su propio discurso" (Lacan, 1974-1975,

7 Jean-Claude Milner escribió el prólogo del libro de Catherine Kintzler, Condorcet, l'instruction publique et la naissance du citoyen [Condorcet, la instrucción pública y el nacimiento del ciudadano] (París, Gallimard, 1984).

8 Podríamos mostrar, pero será el trabajo de otro artículo, que la "genealogía” y la militancia de Foucault también funcionan para descompletar la política, pero sin determinar esta limitación, gracias a la institución de un mínimo legal (aunque algunas de las luchas puedan sin duda conducir a afirmar lo mínimo). Véase la nota 21.

9 Véase el reciente libro de Muriel Fabre-Magnan, L'institution de la liberté [La institución de la libertad] que se enfrenta a estos problemas y pretende tomar nota de la "evacuación imposible de la fundación” instituyendo la "dignidad” como nueva base jurídica. Véanse particularmente las páginas 307 y siguientes.

10 ¿No proporciona el principio de dignidad una base jurídica para negarse a considerar a los seres humanos y sus órganos como mercancías? Pero, por una parte, su estatuto jurídico y su aplicación siguen siendo muy vagos, tanto si se recibe con satisfacción como si se deplora (ibíd., págs. 251 y ss.); por otra parte, incluso si proporciona un fundamento jurídico a esta negativa, sólo puede dejar al Otro y a su mandamiento general de beneficio capitalista fuera de su autoridad.

11 Nota sobre la crítica del principio rector [maître-mot] clave "sociedad". El trabajo "genealógico" de Michel Foucault puede leerse como un despliegue de análisis históricos impulsados por un imperativo general: analizar la constitución de las políticas que tienen por objeto "defender la sociedad". "Hay que defender la sociedad" es el título del curso en el Collège de France, en 1976. La fórmula designa también uno de los temas de Vigilar y Castigar (1975) (la defensa de la sociedad contra la delincuencia, la identificación sociopsicológica de la "peligrosidad” que va más allá de la ilegalidad), y de La voluntad de saber (1994b) (la organización de la sociedad según una política biológica y la defensa de la misma contra los pervertidos). Usemos un vocabulario no foucaultiano: las genealogías identifican y refutan estos principios rectores que obran para el principio rector social: delincuencia, peligrosidad, "perversidad". Describen históricamente las figuras de los diferentes que, en oposición al sujeto vaciado, invaden la ley y demuestran, desde el exterior, la existencia del grupo adecuado de sujetos psicológica y socialmente sanos. Según esta perspectiva, el trabajo genealógico es una contribución muy considerable al pensamiento del minimalismo jurídico-político. Pensemos también en la importante obra de Jean-Claude Milner, Les penchants criminels de l'Europe démocratique (2003) y en la más reciente Considérations sur la France, Conversation avec Philippe Petit (2017). El pensamiento político de Milner se rige, en efecto, por el imperativo de limitar los poderes de la "sociedad". También destacamos la importancia del trabajo de Catherine Kintzler, que aborda esta cuestión de manera directa, al concebir el laicismo como el límite correcto de los poderes de la sociedad

12 Este es el notable interés de la obra de Tristán García: demostrar, a pesar de la evidente simpatía que siente por el “nosotros”, las consecuencias de una política del "nosotros" que se ha erigido en principio: "No hay justicia ni verdad política en el "nosotros"” (p. 259); sólo hay, en el mejor de los casos, una "paz" precaria dedicada a "un desgarro repentino, a una reacción inesperada y poderosa" (p. 258). 